\title{
O Direito, Kafka e a hermenêutica filosófica: $O$ Processo, Evolução histórica das formas de Estado e Direitos Fundamentais.
}

Emerson de Lima Pinto ${ }^{1}$

\begin{abstract}
RESUMO: O presente artigo busca desenvolver uma breve análise da obra de Franz Kafka denominada "O processo", visando proporcionar ao leitor uma compreensão dirigida ao Direito Constitucional e a Ciência Política, tendo como método a hermenêutica filosófica. Vale destacar o capitulo de numero Oitavo (demissão do advogado). Inicialmente, será contextualizado o processo diante de um suposto percurso de transformação do Estado até o Estado Democrático de Direito, em que situa de modo a verificar a principiologia que assegura algumas conquistas fundamentais do processo civilizatório. Existe a possibilidade de um Senhor Josef K. existir no poder Judiciário brasileiro contemporâneo? Essa é uma questão com a qual pretende-se permanentemente dialogar ao longo do presente texto.
\end{abstract}

\begin{abstract}
:
This article seeks to develop a brief analysis of the work of Franz Kafka called "process" in order to provide the reader an understanding addressed to the Constitutional Law and Political Science, with philosophical hermeneutics as method. It is worth noting the chapter eight (resignation of attorney). Initially, the process will be contextualized in the face of a supposed route of transformation of the state to the democratic rule of law, which is located in order to verify the principles, which provides some fundamental achievements of civilization process. There is the possibility of Mr Josef K. exist in contemporary Brazilian judiciary? This is a question we intend constantly talk about throughout this text.
\end{abstract}

Palavras Chave: Kafka e ilegitimidade - Processo - Estado Democrático de Direito e Kafka.

\section{Introdução.}

O desenvolvimento da reflexão em tela dar-se-á no sentido de considerar inicialmente os conceitos admitidos de "ciência do Direito", da "literatura" e acerca da "hermenêutica filosófica". O método hermenêutico propriamente dito no sentido restrito, agora enquanto história das ideias apresenta a origem de certos conceitos fundamentais de um campo científico determinado ou da filosofia, estimulando a articular e apresentar uma interpenetração de certos conceitos, de tal maneira que a partir de uma rede de conceitos é possível desenvolver uma compreensão mais totalizante do objeto, in casu, "O Processo" de Franz Kafka.

\footnotetext{
${ }^{1}$ Advogado. Especialista em Ciências Penais. Mestre em Direito Público. Doutorando em Filosofia. 
No acontecer da verdade ${ }^{2}$ está o elemento da facticidade e, todo o processo de compreensão do ser é limitado por uma história, pela história do ser que limita a compreensão, podendo gerar estranheza naqueles que observam a hermenêutica filosófica como incompatível com a Constituição. E sobre o papel potencial que está contido na hermenêutica filosófica, como tarefa teórica e prática e seu impacto em nosso pensamento, importante transcrever algumas das lições trazidas à tona por ROHDEN:

“O problema da filosofia prática é sua legitimação uma vez que está imbricada com o problema geral da vida humana que, por sua vez, não pode ser restringida apenas a uma perspectiva determinada de conhecer. A filosofia prática, sendo ética, "não se limita a descrever normas vigentes, mas aspira fundamentar sua validez ou introduzir normas mais justas".(...) "De que vale estudar filosofia se tudo que ela lhe permite é discorrer com certa plausibilidade acerca de questões abstrusas de lógica [...] e se ela não aperfeiçoar sua maneira de pensar sobre as questões importantes da vida do cotidiano se não o tornar mais consciencioso do que um jornalista qualquer?"’ ${ }^{\text {. (grifo nosso) }}$

A contribuição que as grandes Revoluções deram origem às diversos conceitos de Estado - Estado Liberal, Estado Social e Estado Democrático de Direito - destacam-se a revolução Inglesa, Norte-americana e Francesa e, posteriormente, Mexicana e Alemã e, por consequência, a transformação dos direitos fundamentais. Ou seja, diante das referidas experiências revolucionárias, criou-se o conceito de um Estado em que os direitos e garantias fundamentais dos cidadãos foram afirmados na base das Constituições ocidentais e, no texto de Kafka não são verificáveis condições que apontem para definições pré-estabelecidas de Estado tendo como referência os modelos antes referidos. No mesmo sentido, existe uma opacidade em relação aos direitos fundamentais assentados na sociedade kafkaniana.

\section{Evolução histórica do conceito de Estado e "O Processo".}

Nos primórdios das formas de Estado - Estado de Direito, Liberal e Social - as relações entre o Estado e a sociedade se refletem no direito administrativo, tendo em vista que as atividades administrativas, nada mais são do que ações realizadas pelo poder público para

\footnotetext{
${ }^{2}$ STEIN, Ernildo. Aproximações sobre hermenêutica. Coleção Filosofia 40. EDIPUCRS. Porto Alegre: 1996, p.70.

${ }^{3}$ ROHDEN, Luiz. Interfaces da Hermenêutica. 1 edição. Editora. EDUCS. 2008, p.149-50. 
atender às garantias e resguardar os direitos fundamentais previstos na Constituição e, que o Estado Kafkaniano ainda está distante de um modelo garantidor de direitos fundamentais.

Em relação aos modelos acima citados, leciona Nelson Saldanha:

"A teoria constitucional contemporânea repousa em larga medida sobre a influência e o exemplo de três fundamentais experiências revolucionárias, que abriram passo ao chamado Estado Constitucional, e que do mesmo modo instauraram, em contextos bastante distintos, a ordem liberal-burguesa que se iria projetar no mundo das últimas gerações. Tais experiências foram a inglesa, a norte-americana e a francesa ${ }^{4}$.

A oralidade da primeira fase defensiva de $\mathrm{Kafka}^{5}$ (no primeiro inquérito) nos lembra os processos estabelecidos na França revolucionária, mas, há ausência de defesa técnica obrigatória no processo penal desta sociedade imaginária.

A começar pela Revolução inglesa e sua consequente formação dos sistemas constitucionais britânicos, Jorge Miranda destaca: a primeira fase iniciada em 1215 com a Magna Carta, cujo destaque ainda não tratava de um texto constitucional codificado, visto que a Inglaterra vivia em um modelo feudal, aliado à limitação do poder monárquico, assim como a consequente afirmação de privilégios à classe dominante ${ }^{6}$, nesse contexto, vem corroborar o que destaca José Afonso da Silva:

Lembremos que a Magna Carta, assinada em 1215 mas tornada definitiva em 1225 , não é de natureza constitucional, "longe de ser a carta das liberdades nacionais, é, sobretudo, uma carta feudal, feita para proteger os privilégios dos barões e os direitos dos homens livres".(...) mas não exclui o fato de que ela se tornasse um símbolo das liberdades públicas, nela consubstanciandose o esquema básico do desenvolvimento constitucional inglês (...) ${ }^{7}$.

$\mathrm{Na}$ sequência no processo histórico inglês, após a criação da Magna Carta, a Revolução de 1688 deu continuidade aos movimentos políticos britânicos. "A Revolução

\footnotetext{
${ }^{4}$ SALDANHA, Nelson. Formação da teoria constitucional. 2.ed.atual.ampl. Rio de Janeiro: Renovar, 2000. p. 50.

${ }^{5}$ KAFKA, Franz. O processo. 3 Edição. Editora brasiliense: São Paulo, 1992. p. 21.

${ }^{6}$ SILVA, José Afonso da. Curso de Direito Constitucional Positivo. 20.ed.rev.atual. São Paulo: Malheiros Editores, 2002.p. 152.

${ }^{7}$ SILVA, José Afonso da. Curso de Direito Constitucional Positivo. 20.ed.rev.atual. São Paulo: Malheiros Editores, 2002. p. 152.
} 
Inglesa, na linha das primeiras cartas de direitos, não pretende senão confirmar, consagrar, reforçar direitos, garantias e privilégios" ${ }^{\prime}$. A ideia de liberdade pública é em vários momentos da obra colocada com claras ambiguidades como vislumbra-se no capitulo segundo onde K. é surpreendido com o primeiro inquérito, aduzindo que: "O senhor pode objetar que não se trata de maneira alguma de um processo, e tem toda a razão, pois é um processo se eu o reconhecer como tal. Mas nesse momento eu o reconheço, de certa forma por piedade" ${ }^{\text {.. }}$

Ambiente diverso foi desenvolvido na Revolução Norte-Americana, no qual originouse da luta contra o poder absoluto dos ingleses em suas colônias, uma vez que o "povoamento do território que iria corresponder aos Estados Unidos da América do Norte coube basicamente a ingleses de formação puritana”. Desse movimento é que se originou um novo regime de governo: o presidencialismo e, da mesma forma, uma nova forma de Estado: a federação que somados a Constituição codificada constituíram em grandes conquistas do processo civilizatório. Nesse sentido, a grande diferença entre as duas formas de sistema constitucional, foi a objetivação dos Estados Unidos da América do Norte em criar uma Constituição escrita de ordem federativa.

Por fim, a Revolução Francesa teve maior importância para o surgimento do constitucionalismo. Fundou-se, principalmente, no exemplo da Revolução Americana. O absolutismo monárquico foi o grande motivo propulsor desta revolução ${ }^{10}$, ou seja, com o advento do iluminismo ${ }^{11}$, bem como com o crescimento da burguesia, do capitalismo, aliados ao protestantismo e o humanismo, tornou-se inevitável o processo de reformulação na forma do Estado Francês ${ }^{12}$.

Com o desenvolvimento econômico e com os pensamentos de igualdade de todos perante a lei, o desejo de uma tolerância religiosa e direito à livre expressão do pensamento, tornou-se inevitável à ocorrência de um movimento político que trouxe à baila a forma absolutista de governo existente na França. Diante das experiências revolucionárias supra mencionadas, assim como de outros acontecimentos históricos que consagraram os chamados

\footnotetext{
${ }^{8}$ MIRANDA, Jorge. Manual de direito constitucional. Preliminares. O Estado e os sistemas constitucionais. $6^{\text {a }}$.ed.rev.atual. Coimbra: Coimbra Editora, 1997. p. 124. tomo I.

${ }^{9}$ KAFKA, Franz. O processo. 3 Edição. Editora brasiliense: São Paulo, 1992. p. 48.

${ }^{10}$ SALDANHA, Nelson. Formação da teoria constitucional. 2.ed.atual.ampl. Rio de Janeiro: Renovar, 2000. p. 68.

${ }^{11}$ RUSSOMANO, Rosah. Curso de direito constitucional. 5.ed.rev.atual. Rio de Janeiro: Freitas Bastos, 1997. p. 3 .

12 MIRANDA, Jorge. Manual de direito constitucional. Preliminares. O Estado e os sistemas constitucionais. 6.ed.rev atual. Coimbra: Coimbra Editora, 1997. p. 160. tomo I.
} 
Direitos Fundamentais $^{13}$, fora necessário o desenvolvimento tanto do Direito Constitucional quanto do Direito Administrativo, a fim de regular as funções do Estado. Ademais, resta evidente que a separação de poderes não é uma realidade no Estado onde reside Josef K., aliás, cumpre denomina-lo de Estado Kafkaniano, visto que o papel que o Tribunal exerce parece ser superior a todos os demais. O próprio contato com essas altas autoridades traz imagem de certo misticismo em relação a onipotência destas "modernas" divindades.

A evolução dos direitos fundamentais veio acompanhada da transformação das formas de organização estatal; inicialmente com o fim do absolutismo ${ }^{14}$, surgindo assim o Estado liberal que após demonstrar sua fragilidade diante das violações individuais e sociais cedeu espaço ao Estado Social, denominado também de Welfare State - Estado de Bem Estar. Este último tinha como prioridade à proteção dos direitos fundamentais e sociais, e pelo qual acabou concedendo espaço ao Estado Democrático de Direito, na qual as garantias e direitos que consolidaram à Constituição.

O nível instituído no Poder Judicial asseveradas no Estado Kafkaniano nos faz pensar sobre sua possível similitude com a justiça tradicional e os denominados juizados especiais, além do abismo existente entre os conflitos que envolvem significativos confrontos patrimoniais, e cuja longa manus operacional na obra de Kafka destaca a cultura violenta Estatal e jurídica que fica evidente na narrativa abaixo:

\section{“ - O inspetor está chamando!}

Foi só o grito que o assustou K., esse grito breve, escandido, militar, de que não julgava o guarda Franz de modo algum capaz. A ordem propriamente dita lhe era muito bem vinda.

- Finalmente! Fechou a chave o armário de parede e foi correndo para o aposento ao lado.

Lá estavam os dois guardas, que o acossaram de volta ao seu quarto, como se isso fosse natural.

- O que é que o senhor está pensando? - bradaram. - Quer se apresentar ao inspetor de camisolão? Ele vai mandar moê-lo de pancadas e nos também." ${ }^{15}$ (grifo nosso)

${ }^{13}$ COMPARATO, Fábio Konder. A Afirmação Histórica dos Direitos Humanos. 3.ed.rev.ampl. São Paulo: Saraiva, 2003.p. 53).

${ }^{14}$ SILVA, Paulo Napoleão Nogueira da. Elementos de Direito Público. Rio de Janeiro: Forense, 1999. p.77.

${ }^{15}$ KAFKA, Franz. O processo. 3 Edição. Editora brasiliense: São Paulo, 1992.p. 15. 
Por seu turno, no Estado Kafkaniano as autoridades tem poderes especiais e uma irresponsabilidade jurídica, eis que os agentes não possuem preocupações com a realização de atos arbitrários, pois sobre eles parece não existir qualquer forma de controle. Seria o Estado Kafkaniano semelhante ao Estado Absolutista?

\section{O Estado de Direito e Liberdades}

A ideia de Estado de Direito teve origem por volta da metade do Século XIX com o objetivo de limitar o poder arbitrário do Estado através de regras jurídicas que contivessem os agentes estatais de práticas violadoras aos cidadãos. Percebe-se, portanto que com o surgimento dessa forma de Estado, a lei e os sistemas sociais, afirmadores dos direitos fundamentais, iniciou por resguardar os direitos individuais frente a supremacia irresponsável dos interesses da administração. Foi concebido como uma maneira de contenção do absolutismo através da lei, como a exercício da soberania popular e não como a vontade do governante ${ }^{16}$.

Diante disso, ou seja, da criação do Estado de Direito em busca de uma liberdade maior e igualitária entre os cidadãos da nação, é cediço que até alcançar essa forma de Estado almejada - em que o indivíduo é o centro das ações estatais, mas que o Estado tem o dever de proporcionar a todos acessibilidade aos direitos e garantias fundamentais - outras formas existiram, assim como: o Estado Liberal e o Estado Social.

Sobre a liberdade e sua fruição "o processo" nos brinda com situações inusitadas como seguem descritas por Kafka:

"- Como posso ir ao banco se estou detido?

- Ah, sim - disse o inspetor, que já estava perto da porta. - O senhor me entendeu mal. É claro que o senhor está detido, mas isso não deve impedi-lo de exercer sua profissão. Tampouco deve ficar tolhido no seu modo de vida habitual.

- Então estar detido não é tão ruim - disse K. e se aproximou do inspetor.

\footnotetext{
${ }^{16}$ LEAL, Rogério Gesta. Teoria do Estado. 2.ed.rev.ampl. Porto Alegre: Livraria do Advogado, 2001. p. 208. 
- Nunca afirmei o contrario - replicou este ${ }{ }^{17}$.

$\mathrm{E}$, no que concerne a liberdade torna-se estranha à passagem inicial quando da anunciada detenção do Senhor Josef K., uma vez que apesar de estar em regime de prisão ele pode continuar agindo naturalmente, eis que inicialmente não possui a sua liberdade de locomoção restrita, podendo continuar dando curso normal a sua vida. Seu delito, não se sabe, tem periculosidade que não o impede de conduzir sua vida com certa naturalidade, uma espécie, de liberdade provisória ou presunção de inocência garante a dúvida sobre o perfil de Estado.

Cumpre destacar, primeiramente, que um dos principais motivos de queda do absolutismo, além da perda do poder para a burguesia, ocorreu em decorrência da teoria da separação de poderes, desta feita o Estado absolutista, "detentor de todo o controle da vida social dos cidadãos" ${ }^{\prime 18}$, perdeu o poder político para a burguesia, que a partir de então, passou a ser considerada como classe social, desta forma "a burguesia, de classe dominada tornou-se classe dominante e, consequentemente, reformulou seus princípios filosóficos de sua insurgência" ${ }^{19}$, demonstrando interesse na formulação de uma Constituição e na aplicação da teoria da separação de poderes, em que as competências de cada setor do Estado não mais pertenceriam a tão-somente um indivíduo. Este grau de desconcentração dos Poderes não parece ter permeado o Estado em que reside Josef K.

O liberalismo baseava-se, principalmente, no indivíduo e suas liberdades, sendo que o papel do Estado era reduzido, ou seja, tão-somente para garantir a segurança dos indivíduos, desde já mediante um texto constitucional. A segurança da sociedade é instrumentalizada pelo seu aparelho repressivo e no Estado Kafkaniano ele parece muito fortalecido. Nesse sentido, no Estado Democrático até mesmo o poder de polícia ${ }^{20}$ estava com o alcance limitado, uma vez que a sua atuação só era permitida em casos excepcionais, isto é, "só podendo limitar o

\footnotetext{
${ }^{17}$ KAFKA, Franz. O processo. 3 Ediçõ. Edtora brasiliense: São Paulo, 1992. p. 21.

${ }^{18}$ MEDAUAR, Odete. Direito Administrativo. 9.ed.rev.ampl. São Paulo: Editora Revista dos Tribunais, 2005. p. 28.

19 BONAVIDES, Paulo. Do Estado Liberal ao Estado Social. 6.ed.rev.ampl. São Paulo: Malheiros Editores, 1996. p. 42.

${ }^{20} \mathrm{O}$ poder de polícia é, em suma, o conjunto de atribuições concedidas à Administração para disciplinar e restringir, em favor do interesse público adequado, direitos e liberdades individuais. (TÁCITO, Caio. Direito Administrativo. São Paulo: Saraiva, 1975. p. 141)
} 
exercício dos direitos individuais para assegurar a ordem pública. A polícia administrativa era essencialmente uma polícia de segurança" ${ }^{21}$.

Os ideais de individualismo e abstencionismo do Estado liberal geraram violências injustificáveis, o que revelou a fragilidade das liberdades burguesas ${ }^{22}$ e, por essa razão, o modelo do Estado abstenceísta começou a ruir dando curso ao recrudescimento da intervenção estatal. Desta feita, um das razões impulsionadoras foi à compreensão exacerbada do Estado Liberal em dar grande ênfase e importância "na liberdade de todos, ou seja, em todos devem ser livres, proprietários e iguais, num sistema alicerçado no império das leis, na separação de poderes e no enunciado dos direitos e garantias individuais".

Mas o juiz de instrução parecia ter sido mais rápido ainda do que K., pois o esperava junto à porta.

- Um momento - disse ele.

K. ficou parado, mas não dirigiu o olhar para o juiz de instrução, e sim para a porta, cuja maçaneta ele tinha agarrado.

- Só queria chamar a sua atenção - disse o juiz - para o fato de que o senhor hoje - ainda não deve ter chegado a sua consciência - se privou de a vantagem de um inquérito, em qualquer causa, representa para o detido.

K. ruiu, filtrando a porta. inquéritos.

-Seus vagabundos - exclamou -, podem ficar com todos os seus

Abriu a porta e desceu correndo as escadas. Atrás dele levantou-se o rumor da assembleia, que voltava a se animar e que provavelmente começava a tecer comentários sobre os incidentes, à maneira dos estudantes" 23

Diante desse ideal, esta forma de contrato social não passava de um acordo entre indivíduos para se criar uma sociedade com o objetivo de proteger a propriedade e promover a segurança, que no Estado Kafkaniano permitia renunciar ao direito fundamental assegurado no plano constitucional. $\mathrm{O}$ acordo da sociedade Kafkaniana não se apresenta em tempo na obra a fim de que possamos depreender com certezas sua legitimidade e legalidade.

\section{O Estado Social e os Direitos Fundamentais e Josef K.}

Estado Social como já informado, tem origem em face das limitações históricas decorrentes do Estado Liberal, portanto essa forma de organização surge de um novo contexto

\footnotetext{
${ }^{21}$ DI PIETRO, Maria Sylvia Zanella. Discricionariedade Administrativa na Constituição de 1988. São Paulo: Atlas, 1991.p. 18.

${ }^{22}$ SILVA, José Afonso da. Curso de Direito Constitucional Positivo. 20.ed.rev.atual. São Paulo: Malheiros Editores, 2002. p. 115.

${ }^{23}$ KAFKA, Franz. O processo. 3 Ediçõ. Edtora brasiliense: São Paulo, 1992. p. 55.
} 
no campo das liberdades: a justiça social. Nessa conjuntura é que emerge o Estado social, ou seja, como "conseqüência direta da revolução industrial, das modernas técnicas de produção em massa, da ascensão das classes trabalhadoras, da formulação de novos direitos" 24 .

No universo do Processo de Kafka verifica-se uma forte intervenção do Estado sobre as liberdades públicas; o fato de que o Sr. K. era funcionário de um Banco (sistema financeiro), o que assegura um modelo de sociedade que apresenta indícios de um capitalismo e, frente a (re) leitura de um diálogo ocorrerá no capítulo oitavo com o comerciante Block, verificará como um patrimônio foi devastado pelo Estado Policial presumido na obra.

A sociedade exige maior intervenção estatal, a fim de se alcançar crescimento econômico e social, garantindo também a igualdade material e não tão-somente formal entre os cidadãos e, em razão dessas garantias individuais, o Poder Público começou a atuar no domínio econômico condicionando as garantias fundamentais ao controle econômico estatal, dispondo assim sobre a organização da vida econômica. Consequentemente a isto, a intervenção realizada pelo Estado emergia essencialmente das ações da Administração Pública, principalmente no que tange o exercício da ação do poder de polícia. Assim sendo, enquanto no Estado Liberal esse poder era exercido somente em casos excepcionais, nesse momento passou a atuar de modo mais abrangente: econômico, social e impor obrigações de fazer aos cidadãos ${ }^{25}$.

Vale ressaltar que um Estado interventivo economicamente pode ter origem em uma concepção social democrática e degenerar para um sistema totalitário, como observa-se na Itália e na Alemanha no amanhecer do século XX. Esses estados, ao molde do kafkaniano o sistema judiciário pautou-se pela obscuridade de normas jurídicas e pela violação de direitos fundamentas anteriormente existentes.

No que concerne a conceituação jurídica contemporânea de diretos humanos, CANÇADO TRINDADE consagra que tais direitos são inerentes a cada ser humano e inalienável; estes por sua vez antecedem os direitos dos Estados, o poder estatal deriva da

${ }^{24}$ SOUZA, Nelson Oscar de. Manual de Direito Constitucional. 2.ed.rev.atual.ampl. Rio de Janeiro: Editora Forense, 1998.p. 18

${ }^{25}$ DI PIETRO, Maria Sylvia Zanella. Discricionariedade Administrativa na Constituição de 1988. São Paulo: Atlas, 1991.p. 24. 
vontade do povo; e de que a justiça prima sobre o direito estatal positivo ${ }^{26}$. Desse modo, no que diz respeito ao conceito dos direitos fundamentais, que estes são direitos que nascem e se desenvolvem com as Constituições com reconhecimentos e os assegurando sua plenitude ${ }^{27}$.

Neste contexto estatal verifica-se que possui grande relevância quando da atuação administrativa por meio do poder de polícia, e em geral na expedição de todos os atos de cunho discricionário. Enuncia-se com este princípio que a Administração, ao atuar no exercício de discrição, terá de obedecer a critérios aceitáveis do ponto de vista racional, em sintonia com o senso normal de pessoas equilibradas e respeitosas das finalidades que presidiram a outorga da competência exercida pelas autoridades.

Por fim, a intervenção estatal não mais seria como nas outras formas de Estado, ou seja, mínima, mas sim um pressuposto legitimador e dotado de coercibilidade e validade, tendo por fim primordial a implementação dos direitos fundamentais que além de oportunizar a liberdade de expressão e agir com base em preocupações sociais, impôs a intervenção estatal como fator fundamental para o alcance do bem comum da sociedade. A coercibilidade, como veremos no Estado em que se desenlaça o processo se dá de modo turvo como verificamos em processos desenvolvidos durante o III Reich que foram razão de aprendizado catastrófico para o processo civilizatório, e que o Estado de Bem Estar Social tem por objetivo afastar-se e impedir retrocessos.

\section{O Estado Democrático de Direito e o garantismo}

O Estado Democrático de Direito surgiu, a partir da decadência das outras formas anteriores de organização estatal e, deste modo, o Estado Liberal se distanciou do Estado Legal, pois desejava uma regulação jurídico-normativa fundamentada no indivíduo, no qual seu principal conteúdo lastreava-se nas diretrizes do liberalismo ${ }^{28}$. Contudo, o individualismo e o abstencionismo do liberalismo deram curso a injustiças, o que originou a necessidade da justiça social. Ainda, na obra "O processo" há um ambiente bastante nebuloso com a presença

\footnotetext{
${ }^{26}$ TRINDADE, Antônio Augusto Cançado. Tratado de Direito Internacional dos Direitos Humanos, Volume I. Sérgio Antônio Fabris Editor. Porto Alegre, 1997, p.19

${ }^{27}$ SARLET, Ingo Wolfgang. A Eficácia dos Direitos Fundamentais. Editora Livraria do Advogado. $2^{\text {a }}$ Ed. Porto Alegre, 2001, p. 37

${ }^{28}$ STRECK, Lenio Luiz; MORAIS, José Luis Bolzan de. Ciência Política e Teoria Geral do Estado. Porto Alegre: Livraria do Advogado, 2000. p. 91.
} 
ostensiva e atuante de dois partidos durante o Inquérito a que está submetido o jovem Josef $\mathrm{K}^{29}$. O processo judicial ou inquisitorial é submetido a uma análise "política" inexplicada/inexplicável na obra e inexplicável ante as atuais referências jurídico-politicas.

No entanto, esses modelos não estavam contidos os direitos individuais de liberdade, isto é, a igualdade social, bem como os direitos fundamentais. Nesse momento surge o Estado Democrático de Direito, abrangendo um novo modelo social, com a inclusão da questão da igualdade, tendo como fator primordial à soberania popular, entretanto a presença de partidos no "processo" não parece segura e eficiente. Assim, o Estado Democrático de Direito surge para superar o modelo de Estado Capitalista e promover à justiça social que as outras formas de Estado não atingiram• a evolução necessária a um melhor processo humanizador.

A democracia se afirmou como asseguradora da proteção das garantias fundamentais, tanto por meio de um governo representativo, quanto, com a participação popular. Nesta feita, a proteção dessas garantias, nada mais é do que a observância das prerrogativas definidas pelos direitos fundamentais e, nesse caminho, Cademartori destaca o conceito de democracia sob a ótica garantista, senão vejamos: "o garantismo redefine o conceito de democracia: É chamado democracia substancial ou social o "estado de direito" munido de garantias específicas, tanto liberais quanto sociais; sendo que a democracia formal ou política será o "estado político representativo", isto é, baseado no princípio da maioria como fonte de legalidade ${ }^{30}$.

De outra banda, verifica-se que "o Estado Democrático de Direito assenta-se na democracia e nos direitos fundamentais" ${ }^{\text {31 }}$, sendo que a Constituição Federal é o instrumento de garantia desses fundamentos. Assim, além das normas ali contidas, é possível encontrar princípios constitucionais que auxiliam nas soluções de demandas complexas, bem como norteiam ações quando existente lacunas e obscuridade no ordenamento jurídico. Situações como concentração de funções no Poder Judiciário constitui uma espécie de ditadura deste Poder, que o decisionismo de Schimmitt legitimou na Alemanha no inicio do século XX. A postura desrespeitosa do réu não pode proporcionar aos agentes estatais reações irracionais

\footnotetext{
${ }^{29}$ KAFKA, Franz. O processo. 3 Edição. Editora brasiliense: São Paulo, 1992. p. 180-1.

${ }^{30}$ CADEMARTORI, Sérgio. Estado de direito e legitimidade: uma abordagem garantista. Porto Alegre: Livraria do Advogado, 1999. p.161.

${ }^{31}$ STRECK, Lenio Luiz. Jurisdição constitucional e hermenêutica: uma nova crítica do direito. Rio de Janeiro: Forense, 2004. p. 110.
} 
como a supressão de fases processuais ou pré-processuais como a renuncia estimulada da realização de Inquéritos pelas autoridades instituídas.

\section{Princípios do Estado Democrático de Direito e similitudes com nosso sistema} jurídico.

No Brasil, a Constituição de 1988 prevê em seu texto a afirmação do Estado Democrático de Direito. O Josef K. existe em nossa sociedade (acusadores invejosos) e são arrastados ao Poder Judiciário. A pena aplicada ao Senhor Josef K. não é admissível em nosso sistema jurídico, exceção caso de guerra declarada, o que não era o caso no Estado Kafkaniano. O modelo brasileiro contemporâneo, felizmente, em processo de concretização possui como destaques: o império da lei, divisão de poderes, legalidade da administração e direitos e liberdades fundamentais ${ }^{32}$. Além disso, outra diretriz fundamental para a existência do Estado Democrático de Direito é a separação de poderes.

Portanto, o ato administrativo praticado pelas autoridades que não observa o princípio da razoabilidade no que se refere a ocidental ideia de devido processo legal, não está em conformidade com a lei e é passível de controle pelo Poder Judiciário no modelo de Estado Democrático de Direito. Entretanto, não se pode falar aqui que o judiciário está invadindo a discricionariedade do administrador pelo simples fato dessa liberdade estar sempre vinculada à Lei e, no Estado Kafkaniano o sistema legal não é transparente.

Nessa trilha reflexiva, José Afonso da Silva leciona:

O princípio da legalidade é nota essencial do Estado de Direito. É, também, por conseguinte, um princípio basilar do Estado Democrático de Direito, como vimos, porquanto é da essência de seu conceito subordinar-se à Constituição e fundar-se na legalidade democrática. [...] É nesse sentido que se deve entender a assertiva de que o Estado, ou o Poder Público, ou os administradores não podem exigir qualquer ação, nem impor qualquer abstenção, nem mandar tampouco proibir nada aos administrados, senão em virtude da lei ${ }^{33}$.

Insta mencionar que a discricionariedade está vinculada ao administrador, não podendo o Judiciário interferir nessa liberdade no E.D.D. O Judiciário deve analisar a

\footnotetext{
${ }^{32}$ LEAL, Rogério Gesta. Teoria do Estado. 2.ed.rev.ampl. Porto Alegre: Livraria do Advogado, 2001. p. 210.

${ }^{33}$ SILVA, José Afonso da. Curso de Direito Constitucional Positivo. 20.ed.rev.atual. São Paulo: Malheiros Editores, 2002.p.419.
} 
proporção utilizada entre o meio e o fim que a lei deseja alcançar, contudo tais limites estão longe de serem esclarecidos como bem fica demonstrado no diálogo entre Josef $\mathrm{K}$ e o sacerdote do presídio no capítulo referente a Catedral, pois como diz o religioso ao réu:"Você sabe que seu processo vai mal? perguntou o sacerdote" ${ }^{34}$.

Os princípios atuam junto à dogmática jurídica de modo pleno, em especial, no controle do poder discricionário dos agentes públicos, uma vez que no âmbito geral do direito e de maneira mais específica, na esfera da discricionariedade, deve haver espaço para a ponderação ${ }^{35}$. Nesse sentido, tanto os princípios expressos em nossa Constituição, como àqueles que decorrem desses e outros tantos, carecem de muita atenção e prioridade quando da execução dos atos administrativos e em manifestações de processos judiciais.

Desde a vigência da Constituição atual, o artigo $5^{\circ}$, inciso LV, torna indiscutível a exigência de observância desse princípio, com os meios e recursos a ele inerentes, e também do princípio do contraditório, em qualquer tipo de processo. Trata-se de um princípio constitucional fundamental, que obviamente deve ser observado. Como reconhece a doutrina, o princípio da ampla defesa deve ser encontrado em todos os procedimentos administrativos e judiciais. Deve ser observado, dando chance ao contraditório e todos os demais princípios que, em meu entendimento, abarcam o princípio da ampla defesa.

Nesse âmbito de reconfigurações positivas ao Estado Kafkaniano na tutela das garantias fundamentais, convém destacar a possível contribuição da teoria geral do garantismo, formulada por Luigi Ferrajoli que "embasa-se no conceito de centralidade da pessoa, em nome de quem o poder deve constituir-se e a quem deve o mesmo servir”. Assim, tem-se que esta teoria, decorrente da teoria garantista penal, possui finalidades a serem seguidas, quais sejam: dignidade humana, paz, liberdade plena e igualdade substancial ${ }^{36}$. Valores esses tão essenciais ao Estado Kafkaniano representado pela dialogo na penumbra

\footnotetext{
${ }^{34}$ KAFKA, Franz. O processo. 3 Edições Editora brasiliense: São Paulo, 1992. p. 227.

${ }^{35}$ BAPTISTA, Patrícia. Transformações do Direito Administrativo. Rio de Janeiro: Renovar, 2003. p. 93.

${ }^{36}$ CADEMARTORI, Sérgio. Estado de direito e legitimidade: uma abordagem garantista. Porto Alegre: Livraria do Advogado, 1999. p. 72.
} 
realizada pelo Senhor. K e Block; Senhor K. e o advogado sobre os mistérios do processo e a suscetibilidade dos julgadores ${ }^{37}$.

Dessa forma, a teoria garantista de Ferrajoli propõe:

(...) a grande antítese entre liberdade e poder que domina toda a história humana, é boa, desejável e defensável a solução que amplia a esfera da liberdade e restringe a do poder, ou, em outras palavras, aquela para a qual o poder deve ser limitado a fim de permitir a cada um o gozo da maior liberdade compatível com a igual liberdade dos demais ${ }^{38}$.

No Estado Kafkaniano o ocultamento das autoridades, bem como a vagueza das normas, e o permanente estado de sofrimento em razão do "processo" e os efeitos que causa a vida do individuo se mostram sob uma sombra permanente na relação de temor referencial ao "Advogado", ao "Tribunal" aos "altos funcionários". O processo de humilhação em que Block $^{39}$ é submetido frente ao Senhor K. pelo seu advogado quando da sua demissão demonstra claramente a dificuldade do sistema judicial a assegurar a ampla defesa. E, nesse sentido, o garantismo é construído a partir de uma estrutura liberal em que o direito e a moral se dividem, se enquadrando dentro do positivismo jurídico do Estado de direito em que a aplicação do princípio da legalidade está inserida na forma de atuação estatal ${ }^{40}$ que poderia trazer um sentido ao processo do Senhor Josef K. e uma solução menos aviltante em seu final.

\section{REFERÊNCIAS BIBLIOGRÁFICAS:}

BAPTISTA, Patrícia. Transformações do Direito Administrativo. Rio de Janeiro: Renovar, 2003.

BONAVIDES, Paulo. Do Estado Liberal ao Estado Social. 6.ed.rev.ampl. São Paulo: Malheiros Editores, 1996

CADEMARTORI, Sérgio. Estado de direito e legitimidade: uma abordagem garantista. Porto Alegre: Livraria do Advogado, 1999.

COMPARATO, Fábio Konder. A Afirmação Histórica dos Direitos Humanos. 3.ed.rev.ampl. São Paulo: Saraiva, 2003.

\footnotetext{
${ }^{37}$ KAFKA, Franz. O processo. 3 Edição. Editora brasiliense: São Paulo, 1992. p. 180-1.

${ }^{38}$ CADEMARTORI, Sérgio. Ibidem, p. 72.

${ }^{39}$ KAFKA, Franz. O processo. 3 Edição. Editora brasiliense: São Paulo, 1992. p. 180-1.

${ }^{40}$ CADEMARTORI, Sérgio. Ibidem. p. 80.
} 
DI PIETRO, Maria Sylvia Zanella. Discricionariedade Administrativa na Constituição de 1988. São Paulo: Atlas, 1991.

KAFKA, Franz. O processo. 3 Edição. Editora brasiliense: São Paulo, 1992.

_ MIRANDA, Jorge. Manual de direito constitucional. Preliminares. O Estado e os sistemas constitucionais. 6 ${ }^{\mathrm{a}}$.ed.rev.atual. Coimbra: Coimbra Editora, 1997.

_ LEAL, Rogério Gesta. Teoria do Estado. 2.ed.rev.ampl. Porto Alegre: Livraria do Advogado, 2001.

MEDAUAR, Odete. Direito Administrativo. 9.ed.rev.ampl. São Paulo: Editora Revista dos Tribunais, 2005.

ROHDEN, Luiz. Interfaces da Hermenêutica. Caxias do Sul, RS: EDUCS, 2008. . Hermenêutica filosófica. São Leopoldo: Editora UNISINOS, 2002.

RUSSOMANO, Rosah. Curso de direito constitucional. 5.ed.rev.atual. Rio de Janeiro: Freitas Bastos, 1997.

SALDANHA, Nelson. Formação da teoria constitucional. 2.ed.atual.ampl. Rio de Janeiro: Renovar, 2000.

SARLET, Ingo Wolfgang. A Eficácia dos Direitos Fundamentais. Editora Livraria do Advogado. 2a Ed. Porto Alegre, 2001,

SILVA, Paulo Napoleão Nogueira da. Elementos de Direito Público. Rio de Janeiro: Forense, 1999.

SILVA, José Afonso da. Curso de Direito Constitucional Positivo. 20.ed.rev.atual. São Paulo: Malheiros Editores, 2002.

SOUZA, Nelson Oscar de. Manual de Direito Constitucional. 2.ed.rev.atual.ampl. Rio de Janeiro: Editora Forense, 1998.

__ STEIN, Ernildo. Aproximações sobre hermenêutica. Coleção Filosofia 40. EDIPUCRS. Porto Alegre: 1996, p.70.

STRECK, Lenio Luiz; MORAIS, José Luis Bolzan de. Ciência Política e Teoria Geral do Estado. Porto Alegre: Livraria do Advogado, 2000.

. STRECK, Lenio Luiz. Jurisdição constitucional e hermenêutica: uma nova crítica do direito. Rio de Janeiro: Forense, 2004.

TÁCITO, Caio. Direito Administrativo. São Paulo: Saraiva, 1975.

TRINDADE, Antônio Augusto Cançado. Tratado de Direito Internacional dos

Direitos Humanos, Volume I. Sérgio Antônio Fabris Editor. Porto Alegre, 1997 